\title{
HOW THE JOURNAL REACHES YOU
}

The ICCA Journal appears four times a year. In order to receive the 1988 Journals, you should subscribe as an ICCA member. The (renewal) fee is now Dutch florins (Hfl.) 50.--, or US \$25.-- for those residing in North America. This annual fee is valid for the years 1988 and 1989. We stress that this fee ought to be net to ICCA, that is, our credit booking, free of all banking charges. However well intentioned they may be, we often receive checks to the amount of Hfl. 50.-- (or equivalent) on which we are charged for banking fees. Since these currently amount to some one-sixth of this subscription rate, they are an imposition. Hence, we beg you, when remitting a cheque or any other form of payment, to arrange that it should be net and free of all charges to the recipient, which, after all, is your own ICCA.

For renewals or new subscriptions, US and Canadian readers are invited (for 1988) to remit US \$25.-- to:

\author{
ICCA \\ c/o Dr. J. Schaeffer \\ Dept. of Computing Science \\ University of Alberta \\ Edmonton / Alberta T6G 2H1 / Canada
}

European readers are invited (for 1988) to remit Hfl. 50.-- to:

\author{
ICCA Europe \\ c/o Prof. dr. H.J. van den Herik \\ P.O. Box 616,6200 MD Maastricht / The Netherlands \\ AMRO BANK no. 450790878 \\ The Postgiro account no. of the AMRO BANK Maastricht, Helmstraat is: \\ 1050085 \\ The address of the AMRO Bank, Helmstraat is: \\ P.O. Box 560, 6200 AN Maastricht / The Netherlands
}

(but as noted below remittances to Dr. Schaeffer are equally acceptable and even preferred.)

Please include a correct statement of your mailing address. (We keep receiving payments without addresses!) Should your mailing label be erroneous or when changing residence, please return an amended label to Dr. Schaeffer or Prof. dr. Van den Herik as the case may require. Those not resident in Europe, the US or Canada are at liberty to remit their dues to either account. However, they are encouraged to use the Treasurer's account, resulting in speedier administration and address handling. More generally, for ease of administration, it is now and will be increasingly in future to have all dues remitted to the ICCA address in Canada.

While stocks last, back issues of the ICCA Journal as from Vol. 6, No. 3 (August 1983) up to Vol. 10, No. 4 are still available at US \$ 6.-- each, US \$ 20.-- for any four and US \$ 80.-- for the set up to Vol. 10 , No. 4. Please order these as you would order or renew a subscription.

For an Institutional Membership, we refer to the Past President's (1986) report, stating, in effect, that they may obtain six copies of all the year's issues for a US \$100.-- annual fee. 